\title{
The Reduction in Total Mortality with Drug-Eluting Stents: Does Emperor has New Clothes?
}

\author{
Abdullah Mohammed Shehab ${ }^{1,2}$, Neelesh Gupta ${ }^{3}$, and Sukri Saliba Sukri Mushahawar ${ }^{2}$ \\ ${ }^{1}$ Faculty of Medicine and Health Sciences, United Arab Emirates University, Al Ain, UAE \\ ${ }^{2}$ Department of Cardiology, Al Noor Hospital, AI Ain, UAE \\ ${ }^{3}$ Asha Niketan Hospital, Bhopal, India
}

Rec Date: Sep 05, 2016, Acc Date: Sep 28, 2016, Pub Date: Sep 30, 2016

Corresponding author: Abdullah Mohammed Shehab, Professor of Cardiology, Consultant Cardiologist, Faculty of Medicine and Health sciences, UAE University, Al Noor Hospital, Al Ain, UAE, Tel: +97137667666; E-mail: a.shehab@uaeu.ac.ae

Citation: Shehab MA, Gupta N, Saliba S, et al. The reduction in total mortality with drug-eluting stents: Does emperor has new clothes? Interv Cardiol J 2016, 2:3.

\section{Short Communication}

Over last 3 decades, percutaneous coronary interventions (PCI) has transformed management of obstructive coronary artery disease (CAD). Commenced with balloon dilation i.e. plain old balloon angioplasty (POBA) of severe obstructive CAD lesions, gradually evolved into stenting started with bare-metal stents (BMS), initially first-generation (stain-less steel) [1] and now contemporary second-generation BMS (cobalt-chromium with thinner struts). BMS was rapidly superseded by drugeluting stents (DES); at first with first-generation (paclitaxeleluting, taxus; and sirolimus-eluting, cypher) now with secondgeneration (zotarolimus-eluting, endeavor; and everolimuseluting, xience) and with ongoing refinements thirdgeneration drug-eluting stents (with biodegradable polymers, polymer-free and biodegradable stents on the basis of poly-Llactide or magnesium) are undergoing trials and many are available for use in contemporary practice.

Interestingly, each time improvement in the technology was need-driven with genuine intent to reduce the shortcomings like restenosis [1] (concern with POBA and BMS) and stent thrombosis [2,3] (concern with first-generation DES).

Over the years, the practice of interventional cardiology evolved. At first practiced solely, now POBA has very restricted indications in contemporary practice, like dilation of the distal anastomotic stenosis of left internal mammary artery with left anterior descending artery (LAD), very focal tandem stenoticaneurysmal lesions (to relieve stenosis, stent is best avoided to prevent stent thrombosis in the adjacent aneurysmal segment), in diabetic patients with acute coronary syndromes with triple-vessel disease (planned for coronary artery bypass, POBA to relieve the obstruction to achieve TIMI 3 flow, if possible) etc. Stenting (with/without pre-dilation) is invariable preferred to treat hemodynamic-significant $(F F R<0.80)$ obstructed coronary artery/arteries. First-generation BMS (having stain-less steel) had high restenosis up to $40 \%$ over initial six to nine months, the second-generation BMS (having cobalt-chromium with rather thinner struts) are in contemporary use with possibly improved restenosis rates. First-generation DES even though having less restenosis rates, had life-threatening stent thrombosis around 1\% per year. To overcome this issue, second-generation DES were invented with thinner struts, increased biocompatibility, and reduced thickness of durable or biodegradable polymers, with different limus (everolimus or zotarolimus) than do first-generation DES. These properties translate into reduced stent thrombogenicity in experimental models and clinically with improved stent thrombosis (possibly $<0.5 \%$ per year) $[4,5]$. However, improved technology came with higher cost, unaffordable by most selfpaying patients in the resource-constrained countries; and in many government-supported health-care systems even in resource-rich countries.

\section{Decrease in All-Cause Mortality with DES: A Sensational News}

Despite frequent attempts to explore any reduction in allcause mortality (despite proven benefits with clinical and angiographic restenosis rates) with use of DES since its popular use in contemporary practice over last 15 years. No study convincingly proved it. The publication of 5-years follow-up results of EXAMINATION [6,7] trial curiously showed reduction in all-cause mortality with DES. EXAMINATION trial, a rather all-comer multicentric European trial recruited 1504 patients with ST-segment elevation myocardial infarction (STEMI) undergoing primary $\mathrm{PCl}$. The trial compared BMS with everolimus-eluting stent (EES), a commonly used secondgeneration DES in many centers around the world. Though it did not show any difference in the mortality at 1-year, [6] upon extending the follow-up for 5 years, the study did show definite difference: the primary endpoint (all-cause mortality and nonfatal myocardial infarction) was significantly lower in patients receiving EES than in those receiving $\mathrm{BMS}$, a benefit that was driven mainly by a lower rate of non-cardiac deaths. Sensational result with thought-provoking message, the only study so far (contrary to all earlier studies conducted with DES) to document reduction in all-cause mortality using DES.

Astutely, investigators in the Norwegian coronary stent trial (NORSTENT), 8 were aware that the findings for BMS have improved, with new stent designs, different metal 
composition, and thinner struts. So, they decided to examine outcomes by comparing second-generation DES with newergeneration BMS in a randomized trial that was pragmatic, inclusive, optimally powered, and non-industry-driven. At the end of 6 years, in patients undergoing $\mathrm{PCl}$, there were no significant differences between those receiving DES and those receiving $\mathrm{BMS}$ in the composite outcome of death from any cause and nonfatal spontaneous myocardial infarction. However as expected, the rates of repeat revascularization were lower in the group receiving drug-eluting stents. NORSTENT trial was rather inclusive $(72 \%$ of patients were enrolled), enrolling patients with all spectrum of patients with CAD (both unstable and stable CAD, unlike EXAMINATION trial having patients with STEMI only). It had much larger number of patients (9013 patients) almost six-folds higher, had $100 \%$ follow-up over 6 years and used all commonly used second-generation DES $(95 \%$ patients received EES or zotarolimus-eluting stents, ZES) and second-generation BMS. Both trials included patients with diabetes mellitus (around $20 \%)$.

\section{The Reduction in All-Cause Cause mortality in EXAMINATION trial: Genuine or Hype?}

In EXAMINATION [6] the primary hypothesis was unproven at 1 year; hence all subsequent analyses, including the new 5year analysis [7] must be viewed as hypothesis-generating. On analysis, the long-term results of EXAMINATION suggest no signals of late attrition in the revascularization benefit in the EES group at 1-year, and no accrued safety hazards compared with BMS, including reassuringly low rates of very late stent thrombosis and target vessel reinfarction, despite dual antiplatelet therapy being discontinued by most patients at 1year. These results are comforting as there is no late increase in dreaded thrombotic events with newer durable polymer drug-eluting stents in patients with STEMI, in contrast with earlier-generation stents [8-10]. Newer drug-eluting stents with thromboresistance properties are perfectly safe in patients with STEMI undergoing percutaneous coronary intervention $[11,12]$.

Curiously, when we look at individual contributions to the mortality endpoint, cardiac causes had only a partial, nonsignificant role $(3.3 \%$ vs $4.9 \%$; $p=0.11$ for EES versus BMS between 1 year and 5 years, respectively), most of the reduction was attributable to non-cardiovascular causes $(1.9 \%$ vs $3.8 \% ; \mathrm{p}=0.03)$, a surprise and thought-provoking finding. Upon further scrutiny of non-cardiovascular mortality in EXAMINATION [7] an excess of cancer-related and sepsisrelated deaths was noted in the BMS group. An observation hard to explain, at present we may at best guess it as play of chance? Imbalances in subclinical cancer at randomization (despite best efforts at randomization) had been known to affect the mortality results as shown in a recent large randomized trial addressing duration of dual antiplatelet therapy following coronary stenting [13].
Up on further extending follow-up of EXAMINATION trial or NORSTENT trial different pattern may emerge. But with the evidences available today, there is no evidence to prove superiority of DES over BMS with regard to all-cause mortality: the emperor has no new clothes.

\section{References}

1. Sigwart U, Puel J, Mirkovitch V, Joffre F, Kappenberger L (1987) Intravascular stents to prevent occlusion and restenosis after transluminal angioplasty. N Engl J Med 316: 701-706.

2. Jensen LO, Thayssen P, Christiansen EH, Maeng M, Ravkilde J, et al. (2016) Safety and efficacy of everolimus-versus sirolimuseluting stents: 5-year results from SORT OUT IV. J Am Coll Cardiol 67: 751-762.

3. Sarno G, Lagerqvist B, Frobert O, Nilsson J, Olivecrona G, et al. (2012) Lower risk of stent thrombosis and restenosis with unrestricted use of 'new-generation' drug-eluting stents: a report from the nationwide Swedish Coronary Angiography and Angioplasty Registry (SCAAR). Eur Heart J 33: 606-613.

4. Stone GW, Rizvi A, Newman W, Mastali K, Wang JC, et al. (2010) Everolimus-eluting versus paclitaxel-eluting stents in coronary artery disease. N Engl J Med 362: 1663-1674.

5. Nasu K, Oikawa Y, Shirai S, Hozawa H, Kashima Y, et al. (2016) Two-year clinical outcome in patients with small coronary artery disease treated with everolimus- versus paclitaxel-eluting stenting. J Cardiol 68: 209-214.

6. Sabate M, Cequier A, Iniguez A, Serra A, Hernandez Antolin R, et al. (2012) Everolimus-eluting stent versus bare-metal stent in STsegment elevation myocardial infarction (EXAMINATION): 1 year results of a randomised controlled trial. Lancet 380: 1482-1490.

7. Sabate $M$, Brugaletta $S$, Cequier A, Iniguez A, Serra A, et al. (2016) Clinical outcomes in patients with ST-segment elevation myocardial infarction treated with everolimus-eluting stents versus bare-metal stents (EXAMINATION): 5-year results of a randomised trial. Lancet 387: 357-366.

8. Bonaa KH, Mannsverk J, Wiseth R, Aaberge L, Myreng $\mathrm{Y}$, et al. (2016) Drug-Eluting or Bare-Metal Stents for Coronary Artery Disease. N Engl J Med 375.

9. Kalesan B, Pilgrim T, Heinimann K, Raber L, Stefanini GG, et al. (2012) Comparison of drug-eluting stents with bare metal stents in patients with ST-segment elevation myocardial infarction. Eur Heart J 33: 977-987.

10. Nakazawa G, Finn AV, Joner M, Ladich E, Kutys R, et al. (2008) Delayed arterial healing and increased late stent thrombosis at culprit sites after drug-eluting stent placement for acute myocardial infarction patients: an autopsy study. Circulation 118: $1138-1145$

11. Kolandaivelu K, Swaminathan R, Gibson WJ, Kolachalama VB, Nguyen Ehrenreich KL, et al. (2011) Stent thrombogenicity early in high-risk interventional settings is driven by stent design and deployment and protected by polymer-drug coatings. Circulation 123: 1400-1409.

12. Palmerini $T$, Biondi Zoccai $G$, Della Riva $D$, Mariani $A$, Genereux $P$, et al. (2013) Stent thrombosis with drug-eluting stents: is the paradigm shifting? J Am Coll Cardiol 62: 1915-1921.

13. Mauri L, Kereiakes DJ, Yeh RW, Driscoll Shempp P, Cutlip DE, et al. (2014) Twelve or 30 months of dual antiplatelet therapy after drug-eluting stents. N Engl J Med 371: 2155-2166. 
